\title{
Medievalista
}

Online

$21 \mid 2017$

Número 21

\section{Palmela. O espaço e as gentes (séculos XII-XVI)}

Tese de Doutoramento em História apresentada à FCSH-NOVA, Julho de 2016. Orientação dos Professores Doutores Bernardo Vasconcelos e Sousa e Luís Filipe Oliveira

João Costa

\section{(2) OpenEdition}

\section{Journals}

Edição electrónica

URL: http://journals.openedition.org/medievalista/1297

DOI: 10.4000/medievalista.1297

ISSN: 1646-740X

\section{Editora}

Instituto de Estudos Medievais - FCSH-UNL

Refêrencia eletrónica

João Costa, « Palmela. O espaço e as gentes (séculos XII-XVI) », Medievalista [Online], 21 | 2017, posto online no dia 01 junho 2017, consultado o 23 setembro 2020. URL : http://journals.openedition.org/ medievalista/1297; DOI : https://doi.org/10.4000/medievalista.1297

Mediavalista está licenciado com uma Licença Creative Commons - Atribuição-NãoComercial 4.0 Internacional 
Título: Apresentação de Tese / Thesis presentation: Palmela. O espaço e as gentes (séculos XII-XVI)

Tese de Doutoramento em História apresentada à FCSH-NOVA, Julho de 2016.

Orientação dos Professores Doutores Bernardo Vasconcelos e Sousa e Luís Filipe Oliveira Autor(es) / Author(s): João Costa

Universidade / Universit: Universidade Nova de Lisboa

Faculdade e Departamento / Unidade de Investigação - Faculty and Department /

Research Center: Faculdade de Ciências Sociais e Humanas, Instituto de Estudos

Medievais; Centro de Estudos Históricos

Código Postal / Postcode: 1069-061

Cidade / City: Lisboa

País / Country: Portugal

Email Institucional / Institutional email: jtscosta86@gmail.com

Fonte: Medievalista [Em linha]. Direc. Bernardo Vasconcelos e Sousa. Lisboa: IEM.

Disponível em:

http://www2.fcsh.unl.pt/iem/medievalista/MEDIEVALISTA21/costa2110.html

ISSN: 1646-740X

Data de recepção do texto / Received for publication: 27 de Setembro de 2016 


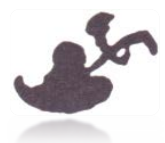

\section{Apresentação de Tese / Thesis Presentation: Palmela. O espaço e as gentes (séculos XII-XVI)}

\section{João Costa}

\section{O objecto ${ }^{1}$}

A consideração de que estamos perante uma vila fundamental no contexto da reconquista portuguesa e fulcral no estudo e no entendimento da própria história da Ordem de Santiago em território português, tendo constituído uma das suas sedes, conjugava-se para tornar atractiva e desafiante a análise deste objecto.

Tendo como intento apriorístico estudar as relações de poder em Palmela na Idade Média, era absolutamente necessário definir os limites do território em estudo e perceber se concelho e comenda eram, fisicamente, realidades diferentes - tendo, obviamente, noção de que se trata de conceitos distintos, relativos a entidades institucionais diversas, embora com interacção entre si. A investigação que conduzimos veio, efectivamente, comprovar a sobreposição das duas circunscrições, razão pela qual optámos por considerar o uso do conceito de "território” ao invés dos de “concelho” ou “comenda” de modo a não ferir a conceptualidade das duas expressões.

Depois, foi necessário definir a cronologia de abordagem. Neste sentido, há, desde logo, um problema na consideração do que é a Idade Média. Assim, decidimos estender a nossa análise à longa duração, isto é, enquadrar o estudo entre 1147, data da primeira conquista cristã de Palmela e 1551, momento da incorporação do Mestrado da Ordem de Santiago na Coroa Portuguesa, o que teve como consequência a tomada de posse do convento pela Coroa.

\footnotetext{
${ }^{1} \mathrm{O}$ texto integral dos dois volumes que compõem esta tese, na sua versão não corrigida, poderão ser consultados em:

https://www.academia.edu/27111160/Palmela_o_espa\%C3\%A7o_e_as_gentes_s\%C3\%A9culos_XII$\mathrm{XVI}$
} 


\section{Objectivos}

Definidos o objecto e a cronologia, determinámos desde logo que o principal objectivo passaria pela análise das relações institucionais ocorridas neste território, porque dessa leitura resultaria quer a capacidade de estudarmos o enquadramento social e institucional em Palmela, quer o seu reflexo na construção, gestão e interpretação do espaço em que esses mesmos poderes se moviam.

Esta opção permitiu-nos, pois, observar a organização da hierarquia local, partindo do topo para a base, discernindo-se nesta leitura processos de ascensão social. Do mesmo modo, da interacção entre as diversas instituições foi possível entender os vários momentos da vida deste território, explicando, por vezes, o seu próprio desenvolvimento e/ou contracção.

Relativamente ao espaço, a opção passava substancialmente por tentar demonstrar uma convicção, fundamentada em fontes outrora já consultadas, de que também em Palmela encontramos testemunho da imposição de um urbanismo religioso-militar; não pautado pelo traçado regular que encontramos em Sines, Setúbal, Tomar ou Évora, mas pela construção de uma igreja que reordena em seu redor todo o crescimento da vila baixa de Palmela.

\section{Metodologia}

Para tudo isto concorreu a aplicação de uma metodologia específica com vista a atingirmos os objectivos definidos a priori.

Logo à partida, a pesquisa arquivística revelava-se um desafio. Estudar quatrocentos anos de história de um território tão vasto e com ramificações institucionais tão variadas não se afigurava uma tarefa fácil, sobretudo quando definimos como regra o levantamento sistemático e completo de toda a informação relativa a todos os indivíduos que demonstraram ter uma relação directa com Palmela, quer habitando no seu território quer explorando propriedades no mesmo. Daqui resultou o levantamento de cerca de três milhares de documentos, entre simples e compostos, que enquadrámos 
numa base de dados, construída para o efeito, por forma a organizarmos devidamente toda a informação recolhida.

Se consideramos que o levantamento documental foi o mais completo possível, a verdade é que deveria tê-lo sido ainda mais. Foi demasiada a documentação à qual não tivemos acesso, quase exclusivamente na Torre do Tombo. Trata-se sobretudo de documentos que sendo relativos a capelanias conventuais, outros de cronologias situadas nos séculos XIII-XIV (onde a documentação escasseia), ou a documentação relativa ao cartório da milícia, que permitiria a resolução de muitas questões deixadas em aberto, e ajudaria a completar o mapa dos temas que tratamos nesta tese. Aproveitamos, portanto, para deixar aqui uma crítica dura ao que consideramos ser um fenómeno de apropriação e de patrimonialização dos documentos por parte da Torre do Tombo e que a todos nós deveria preocupar.

Problemas à parte, optámos por aplicar o método prosopográfico à análise deste território. Daqui resultou o segundo volume apenso a esta tese, extenso em virtude de considerarmos todos os indivíduos com relação comprovada com Palmela. Este volume, aliás, constituiu a base de quase todo o trabalho desenvolvido, uma vez que o cruzamento da informação nele contida permitiu-nos abordar todas as questões que releváramos inicialmente.

\section{Enquadramentos}

Este estudo encontra-se organizado em três partes: enquadramentos, conjunturas e estruturas.

No primeiro, procurámos sobretudo enquadrar Palmela em termos geográficos, abordando os seus perímetros jurisdicionais, as vias de comunicação que estabelecia com o exterior do território e a análise dos dados demográficos de que dispomos para o seu estudo.

Em termos geográficos e jurisdicionais, importa perceber que o papel geoestratégico de Palmela foi absolutamente crucial em alguns momentos da História Portuguesa, nomeadamente nos séculos XII-XIII, durante o avanço cristão rumo ao Algarve. 
Palmela constituiu um posto avançado quer de vanguarda da ofensiva, quer de atalaia na defesa da retaguarda do futuro reino português, e também durante as investidas castelhanas dos séculos XIV-XV, tomando sempre este território voz pelo monarca português.

Esta localização privilegiada, num território composto por cerca de dois terços da península de Setúbal, atesta-se na proliferação de vias de comunicação terrestes que ligavam o núcleo urbano ao seu alfoz, vias estas coadjuvadas pela possibilidade de navegação pelo canal da ribeira de Corva e do Livramento que desaguavam no rio Sado. Igualmente, a ligação de Palmela ao mar, sobretudo junto do Outão e através do estuário do Sado, e ao estuário do Tejo, a Norte, até meados do século XIV, conferiam à vila e ao seu território uma dinâmica comercial e económica considerável que tem, até hoje, sido esquecida pela historiografia.

Relativamente aos perímetros jurisdicionais, importa destacar dois momentos: um primeiro, desde 1186, quando D. Afonso I doa Palmela à Ordem de Santiago, até meados do século XIV, e onde a referida dinâmica económica seria significativa; e um outro, daí em diante, onde a ligação marítima e estuarina se dilui com a autonomização dos territórios a Norte e a Sul da península, e que constitui o momento do declínio e da perda relativa de importância de Palmela face a Setúbal.

Quanto aos aspectos demográficos, os dados recolhidos até finais do século XV são poucos e advêm, sobretudo, da consideração da presença de igrejas, róis de besteiros, existência de tabeliães, e de outros dados indirectos. Só no século XVI ganhamos uma mais exacta noção da realidade demográfica em Palmela. Podemos considerar, também aqui, vários períodos. Um primeiro, até finais da década de 1520, onde os quantitativos se mantêm mais ou menos estáveis, seguindo-se um segundo período de quebra acentuada da população em virtude de cataclismos sísmicos e de surtos pestíferos. Os dados que podemos ler para 1532 e 1534 são, a nosso ver, erróneos. É nossa convicção que o levantamento do Numeramento é anterior à quebra demográfica, sendo depois repetido na visitação da Ordem de Santiago. A informação dada pela visita da Ordem de 1552, mais completa e organizada, permite, sim, pelo modelo escolhido pelos oficiais da milícia, disponibilizar uma visão mais fidedigna da realidade demográfica. 


\section{Conjunturas}

Numa segunda parte, procurámos localizar o objecto "Palmela” na História Portuguesa, considerando para o efeito quatro períodos. O primeiro, respeitante aos dados préhistóricos, discorrendo até ao controlo cristão da praça em 1147, destina-se, sobretudo, a percebermos as razões do assentamento, na longa cronologia, de comunidades humanas neste território, ajudando a sua análise na leitura da própria evolução do espaço físico de Palmela.

O período de 1147 a 1218 é já o primeiro em que Palmela se encontra sob domínio cristão. Importa aqui perceber que a consolidação deste espaço por parte da Ordem de Santiago foi pautada por avanços e recuos, mercê das ofensivas bélicas almóadas (1184 e 1191) que arrasaram o território. Não obstante, datará de finais do século XII a instalação na alcáçova do castelo da primeira sede conventual da Ordem em Portugal apesar da viabilidade da hipótese de Alcácer como primeira casa da milícia em solo português. O controlo efectivo da península de Setúbal a partir da praça-forte de Palmela foi fundamental no avanço das forças cristãs para Sul rumo a Alcácer, bastião islâmico. A conquista desta praça alentejana e a consequente mudança do convento de Palmela para Alcácer representará o início de uma nova fase na vida de Palmela.

Apesar de ser o maior período que considerámos na nossa análise, a verdade é que a documentação até aos meados do século XV escasseia, sobretudo a que diz respeito à Ordem de Santiago - exceptuam-se alguns documentos relativos ao Mosteiro de Santos. É uma época em que o território passa por algumas mutações físicas, sobretudo no seu castelo e na evolução do núcleo urbano, e institucionais, com uma autonomização face à diocese de Lisboa, que passa de uma posição de supervisão para outra de mero receptáculo da terça eclesiástica, ou pelo surgimento de outras casas religiosas, com destaque para os homens da pobre vida de Alferrara, que aí se instalam na década de 1380. Este período é também marcado pelo início da construção da nova casa conventual da Ordem, que perduraria, embora mais tarde já noutros moldes, até à extinção da Ordem já no século XIX. Com construção iniciada, tudo indica, em 1443, terá sido estreada em 1482, embora consideremos que o edifício continuou a ser sistematicamente alvo de obras e de melhoramentos ao longo das décadas seguintes. 
O derradeiro período acaba por ser marcado por uma época de recuperação económica e demográfica e também pelo seu oposto, tal como referimos anteriormente. As vicissitudes do tempo assim o ditaram. Apesar disto, o que marca fortemente esta fase é mesmo a instalação conventual na medina do castelo. As relações sociais, hierárquicas e económicas que estabelece com a vila são deveras significativas. Por outro lado, a assimilação, em 1526, da comenda pelo convento, desaparecendo a figura do comendador, é sintomática da afirmação da casa conventual no contexto da Ordem. Por esta razão, considerámos 1551 como terminus ad quem deste estudo. A tomada de posse do Rei sobre o convento, seguida à morte do Mestre D. Jorge, marca indelevelmente uma mudança paradigmática face ao período medieval, entrando Palmela, a nosso ver, definitivamente na Era Moderna.

\section{Estruturas}

São os homens e as instituições a que pertencem que provocam o próprio devir do espaço em que se inserem e são eles mesmos os motores da história. Tratando-se de um território tutelado pela Ordem de Santiago, colocámos à cabeça esse mesmo senhorio, dividindo a sua análise entre os aspectos relacionados com o convento e aqueles outros relativos à comenda, entendendo que se trata de duas dimensões institucionais distintas e que só a partir de 1526 se assumiram como uma só.

Uma vez que este esforço de síntese a tal obriga, destacamos apenas alguns aspectos. Em primeiro lugar, a evolução da própria sede conventual, que acompanha os ritmos da reconquista cristã e cuja implantação local está em boa medida por explorar em Alcácer do Sal e, sobretudo, em Mértola. Depois, importa perceber que a orgânica conventual interna não é imutável ao longo dos séculos e que difere, por exemplo, de Alcácer para Palmela - não obstante os dados embrionários de que dispomos para a vila sadina. Por outro lado, perceber também que, sobretudo durante o Mestrado de D. Jorge, há uma preocupação em manter os quantitativos humanos estáveis, promovendo o que chamámos de senhorialização do convento, favorecendo o Mestre a inclusão de indivíduos ligados à sua Casa Senhorial. Por fim, destacamos as bases geográficas de extracção dos freires conventuais, onde parece privilegiar-se uma matriz local com destaque, como podemos constatar, para as vilas de Palmela e Setúbal. 
Quanto à comenda, ao nível do espaço parece-nos existir uma ingerência da Ordem na formulação do núcleo urbano e uma monopolização do património urbano e rural. Relativamente à sua hierarquia, assistimos já no século $\mathrm{XV}$, na cúpula, a um interessante fenómeno de assimilação da comenda com a alcaidaria-mor por parte, claramente, de Antão de Faria e de Francisco de Faria e, possivelmente, anterior a ambos, de Nuno da Cunha, todos eles cavaleiros da Casa do Rei.

Quanto ao concelho, destacamos, desde já e sobretudo, a permeabilidade e, mesmo, a promiscuidade entre os oficiais do concelho e a Ordem de Santiago. Muitos deles são referidos como escudeiros ou cavaleiros da Casa do Mestre e, desde logo, fiéis à milícia. Alguns deles cumprem um verdadeiro cursus honorum na construção de uma carreira política alicerçada quer no património que detinham, quer na efectiva ligação à Ordem de Santiago.

Relativamente à Coroa, parece quase omissa em Palmela ao longo destes quatro séculos de História. Salvaguardam-se as doações feitas ainda nos séculos XII-XIII e algumas determinações judiciais, sobretudo em matéria criminal e já no século XV. O seu papel passará sobretudo pelo de fiel da balança na relação entre a Ordem de Santiago, o concelho e outras instituições em relação neste território.

Por último, há toda uma série de relações que se estabelecem entre Palmela, concelho, e Palmela, comenda, quer civis, como sejam os concelhos vizinhos, onde enquadramos, também, Lisboa, quer religiosos, sobretudo as casas religiosas de Santos, S. Vicente de Fora, Gafaria de Almada, Convento de S. Paulo de Alferrara e Mosteiro de Nossa Senhora da Piedade de Azeitão e o Convento do Carmo de Setúbal. Destas últimas, ressaltamos sobretudo a acumulação de património que vão conseguindo, constituindo autênticos feudos em território monopolizado pela milícia. Das relações interconcelhias destaca-se a conflitualidade latente com Setúbal ao longo de toda a Idade Média e que se prolonga pelo século XVII em diante, claramente advinda da autonomização da vila sadina em 1343 e que influencia, parece-nos, a própria relação de cordialidade entre Palmela e Sesimbra, vila que tinha também com Setúbal várias contendas. 


\section{Conclusões}

Sintetizando, no possível, as conclusões gerais desta tese, parece-nos existir um modelo urbanístico da Ordem de Santiago na vila de Palmela, modelo este que, para além de condicionar o desenvolvimento da tessitura urbana, permite ordenar as relações sociais, políticas, económicas e religiosas na vila.

Depois, percebe-se claramente uma monopolização do território por parte de Ordem de Santiago, processo que passa pelo controlo das estruturas políticas e económicas, constrangendo os processos de ascensão social e daí resultando um claro apagamento da acção da Coroa e da Diocese de Lisboa, e impondo condições à acção do concelho. Por outro lado, revelou-se óbvia a permeabilidade entre a oligarquia local e a milícia espatária, assim como o recurso ao recrutamento local por parte da Ordem, sobretudo para o provimento da sua comunidade conventual religiosa e leiga.

Por fim, é certo que várias questões foram sendo levantadas ao longo destas cerca de trezentas e cinquenta páginas. Não podendo aqui indicar todas, limitamo-nos a referir algumas, nomeadamente a necessidade de estudar os processos de acumulação de património fundiário e da sua posterior alienação por parte da Ordem. Importa igualmente desenvolver estudos sobre a evolução morfológica e a percepção dos usos da medina e da alcáçova do castelo, cujas conclusões actuais são claramente deficitárias. Neste contexto, há que estudar a construção urbana da vila baixa de Palmela, sobretudo o seu centro vital e o novo bairro de S. Sebastião. Por fim, aprofundar o estudo das comunidades da Ordem em Alcácer e Mértola parece-nos fundamental para percebermos a mobilidade dos membros da milícia, sobretudo em função do nomadismo da casa conventual. E, claro, o estudo de Setúbal, e das demais localidades do antigo termo de Palmela, designadamente se acompanhado de um ficheiro prosopográfico que o complemente, permitirá completar alguns dados relativos a Palmela. 


\section{COMO CITAR ESTE ARTIGO}

\section{Referência electrónica:}

COSTA, João - “Apresentação de Tese / Thesis Presentation: Palmela. O espaço e as gentes (séculos XII-XVI).”. Medievalista 21 (Janeiro-Junho 2017). [Em linha] [Consultado dd.mm.aaaa]. Disponível em http://www2.fcsh.unl.pt/iem/medievalista/MEDIEVALISTA21/costa2110.html ISSN 1646-740X.

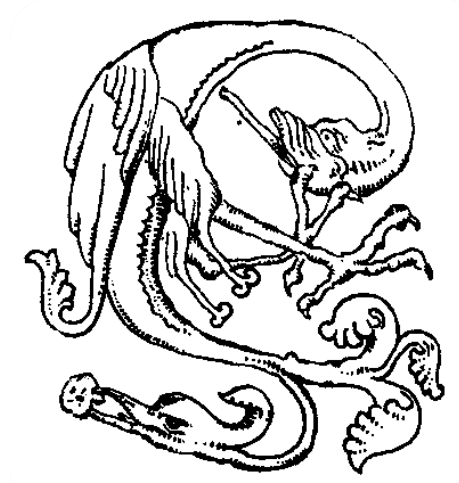

